\title{
Role of Wavelength Division Multiplexing Scheme in Free Space Optical Communication Systems
}

\author{
Bindu Sharma \\ Research Scholar \\ Department of ECE \\ Sri Sai University, Palampur
}

\author{
Veena Kumari Thapa \\ Research Scholar \\ Department of ECE \\ Sri Sai University, Palampur
}

\author{
Abhishek Sharma \\ Assistant Professor \\ Department of ECE \\ Sri Sai University, Palampur
}

\begin{abstract}
Swift demand of data rate supporting advanced number of end consumers at high speed has steered researchers to harvest Free Space Optics (FSO). This work is focused on engaging 2 $\times 10$ Gbps return-zero (RZ) encoded wavelength-division (WDM) multiplexed Free Space Optics Communication system. The signal received is analyzed using BER analyzer and Eye diagrams
\end{abstract}

\section{Keywords}

RZ, WDM, BER, Eye Diagram

\section{INTRODUCTION}

We ask that authors follow some simple guidelines. In essence, we ask you to make your paper look exactly like this document. The easiest way to do this is simply to download the template, and replace the content with your own material. Traditional radio systems are fronting encumbrance in designing due to demand of data for diversity of new services. Researchers have developed a contemporary communication system that reveals the properties of prevailing wireless and optical fiber communication technologies, named as Free Space Optical Communication (FSO) [1]. Contemporary FSO system has been mostly explored to take advantages of existing wired optical communication [2]. FSO concentrate on strengthening of communication by assimilating point to point laser signals. FSO provides huge bandwidth, unregulated spectrum, cost effective implementation and low input power as compared to traditional wired fibers [3-4]. FSO also provides alternate to the locations where the deployment of wired network is hard to reach. Despite all these advantages, FSO system is affected by rain, fog, refractive index variation etc. [5-7]. Many researchers have provided different solution to deal with such issues over the years [8-11]. Another issue that is to be addressed is system capacity. Many researchers have employed different multiplexing schemes and even advanced novel one. One such scheme which is widely used in optical communication is known as wavelength division multiplexing (WDM) [12-48]. In this work, we emphasize on the high speed long reach FSO system. To replicate that we employ return-zero modulation format in two different channels each with data rate of $10 \mathrm{Gbps}$ and wavelengths $1550 \mathrm{~nm}$ and $1551 \mathrm{~nm}$. The signal is multiplexed using WDM and the channel used is free space of the range $20 \mathrm{Km}$. The receiver consist of photo diode followed by low pass filter and bit error rate analyser. The rest of the paper is organized as, Section II consists of system description, result and discussion is presented in Section III and Section IV concludes the paper.

\section{SYSTEM DESCRIPTION}

The proposed system is modelled using OptiSystem ${ }^{\mathrm{TM}}$ software as shown in Fig. 1. The system contains two transmitter channels each consists of pseudo-random bit sequence (PRBS) generator. PRBS provides $10 \mathrm{Gbps}$ of data rates which is subjected to return-zero (RZ) encoder. For carrier we have use continuous-wave $(\mathrm{CW})$ laser as source. The RZ encoded information signal and carrier signal is modulated in mach-zander modulator (MZM). This modulated signal from each transmitter is then fed to WDM multiplexer and output obtained $2 \times 10 \mathrm{Gbps}$ data is sent over the free space channel of the length $20 \mathrm{Km}$. At the receiver the signal is de-multiplexed and sent to the respective section corresponding to the wavelength. The section contains photo detector, we have used PIN diode as photo detector. Then a low pass filter section is used to omit any unwanted component and final the signal is tested and analysed using BER analyser. The parameters of the components used in system for simulation are shown in table 1 .

Table 1: Component Parameter

\begin{tabular}{ccc}
\hline Sr. No. & Parameter & Value/Type \\
\hline 1. & Operating Wavelength (nm) & 1550 for Channel \\
& & 1 \\
& & 1551 for Channel \\
& & 2 \\
2 & Input Power (dBm) & 0 \\
3 & Link Distance (Km) & $1600-2200$ \\
4 & Amplifier Gain (dB) & 14 \\
5 & Noise Figure (dB) & 4 \\
6 & Data Rates (Gbps) & 10 per Channel \\
7 & Tx and RX Aperture & 20 \\
8 & Diameter (cm) & 1 \\
9 & Photodiode & 10 \\
10 & Desponsibility (A/W)
\end{tabular}

\section{RESULTS AND DISCUSSION}

The proposed FSO link is varied from $16 \mathrm{~km}$ to $20 \mathrm{Km}$ for analysing the system response. Figure 2 signifies system performance in terms of minimum bit error rate and maximum Q factor with respect to free space optics range. Fig. 2 a) indicates minimum BER obtained for channel 1 as $1.57 \times 10^{-}$ $32,9.00 \times 10^{-19}$ and $5.91 \times 10^{-12}$ over the free space optics range of $16 \mathrm{Km}, 18 \mathrm{Km}$ and $20 \mathrm{Km}$ respectively. The minimum BER obtained for channel 1 as $2.82 \times 10^{-35}, 9.91 \times$ $10^{-20}$ and $8.60 \times 10^{-13}$ over the free space optics range of 16 


\section{$\mathrm{Km}, 18 \mathrm{Km}$ and $20 \mathrm{Km}$ respectively.}

Similarly, Fig 2 b) indicates maximum Q factor obtained for channel 1 as $11.80 \mathrm{~dB}, 8.76 \mathrm{~dB}$ and $6.78 \mathrm{db}$ over the free space optics range of $16 \mathrm{Km}, 18 \mathrm{Km}$ and $20 \mathrm{Km}$ respectively. The maximum $\mathrm{Q}$ factor obtained for channel 2 as $11.80 \mathrm{~dB}$, $8.76 \mathrm{~dB}$ and $6.78 \mathrm{db}$ over the free space optics range of 16 $\mathrm{Km}, 18 \mathrm{Km}$ and $20 \mathrm{Km}$ respectively.

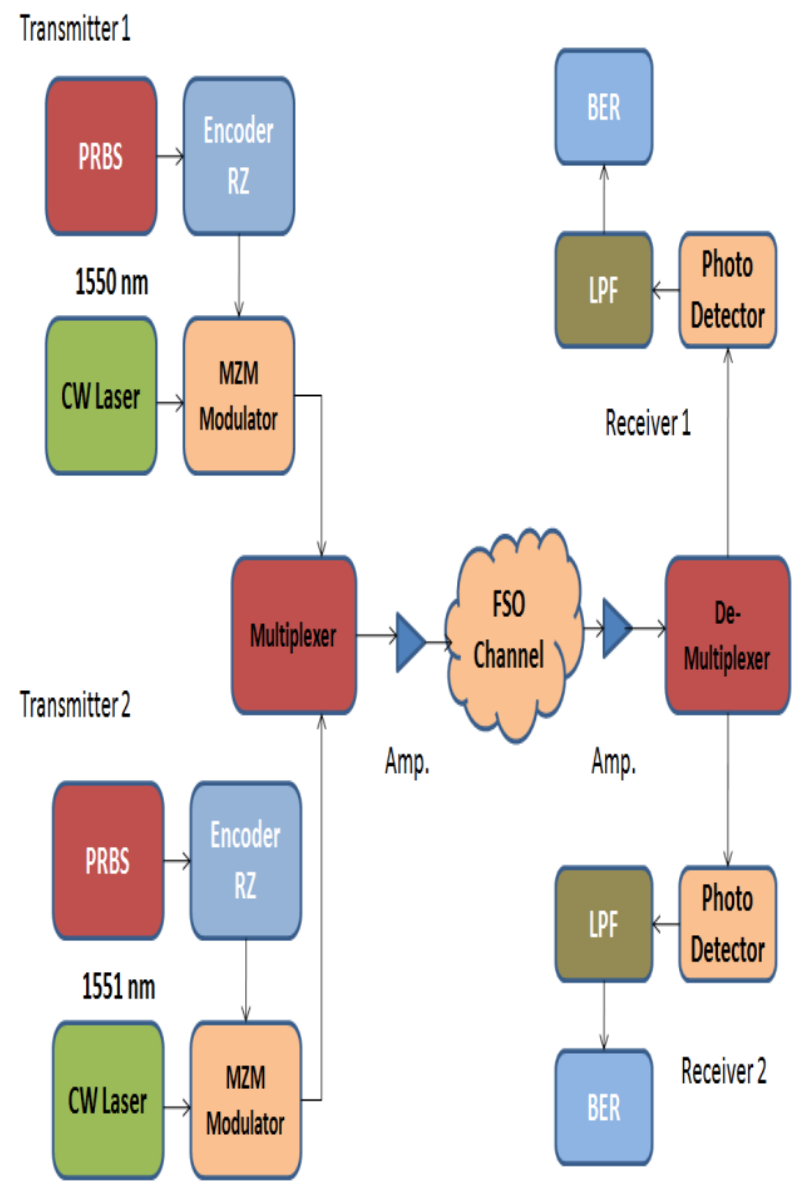

Fig.1 Proposed $2 \times 10$ Gbps FSO system

冒

Min. BER (Range (km))

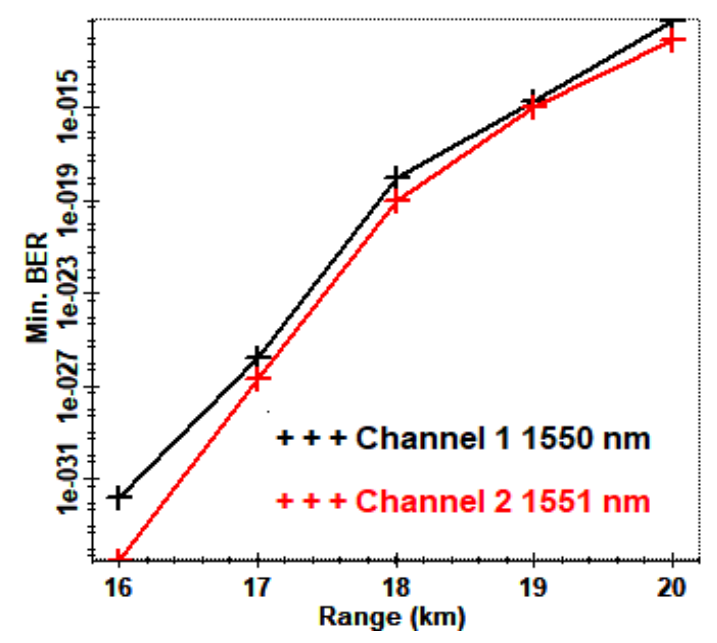

(a)
曷

Max. Q Factor (Range (km))

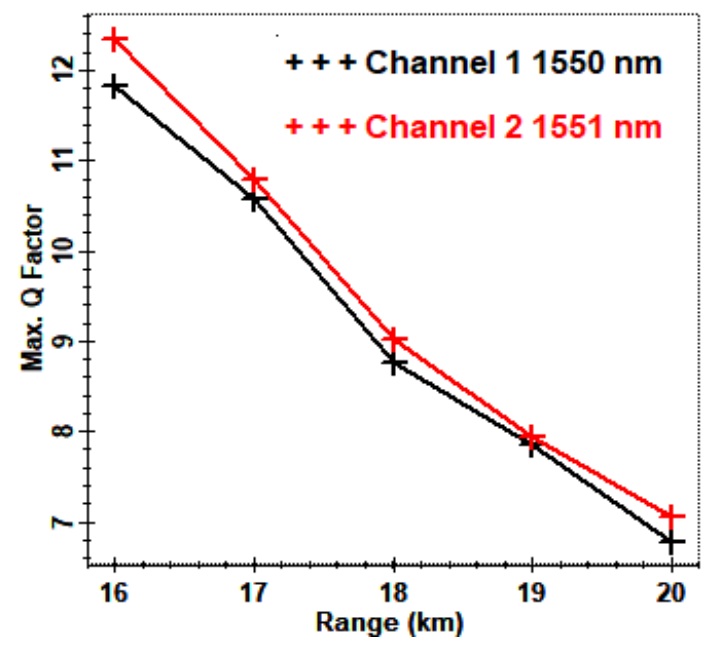

(b)

Fig. 2 a) Min. BER Vs Range for Channel 1 and Channel 2 and b) Max. Q factor Vs Range for Channel 1 and

Channel 2

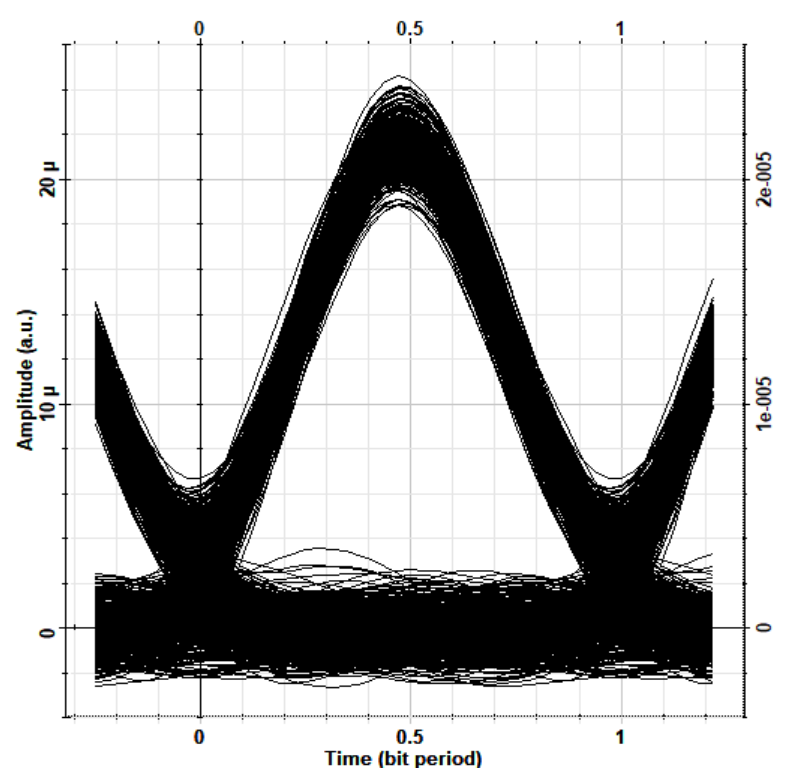

(a) 


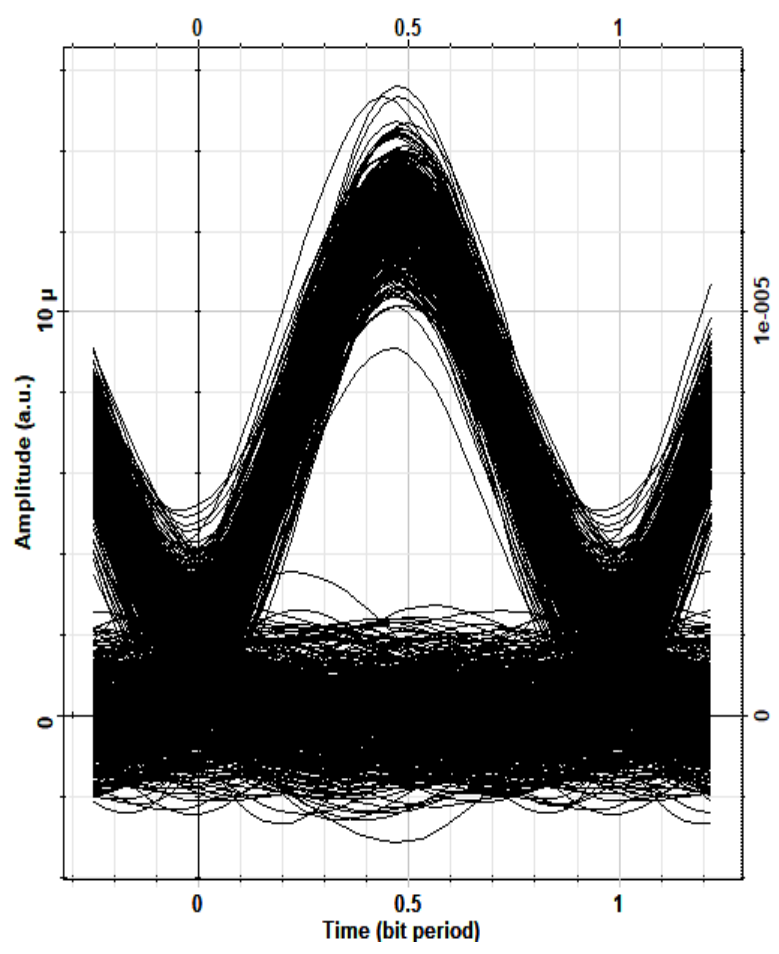

(b)

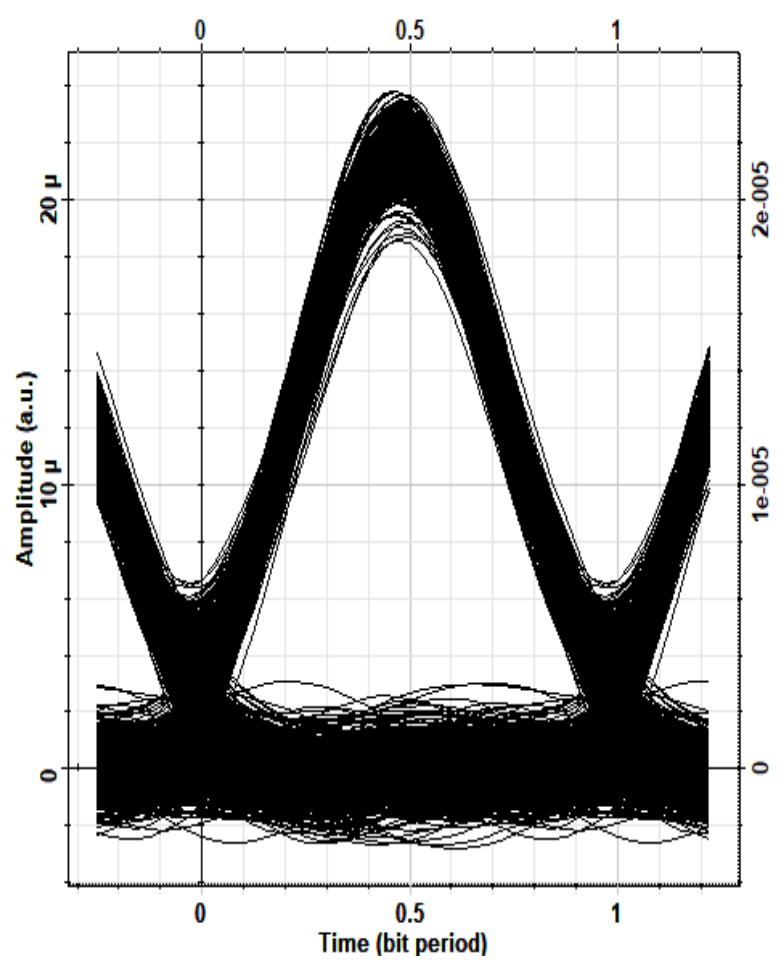

(c)

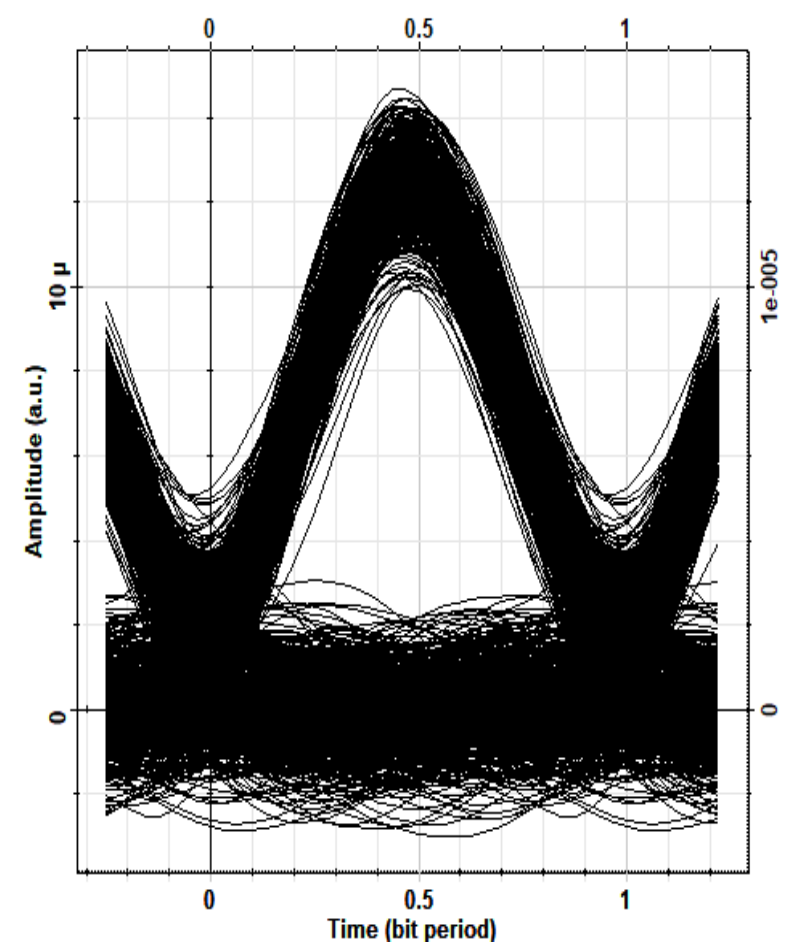

(d)

Fig 3 Eye Diagram: a) and b) represents eye diagram for channel 1 at $16 \mathrm{Km}$ and $20 \mathrm{Km}$ and b) represents eye diagram for channel 2 at $16 \mathrm{Km}$ and $20 \mathrm{Km}$ and

Fig. 3 indicates the eye diagram for channel 1 and 2 at the receiver end at $16 \mathrm{Km}$ and $20 \mathrm{Km}$ respectively. Clear opening of the eye indicates reception of the signal at the receiver terminal with acceptable $\mathrm{Q}$ factor and BER.

\section{CONCLUSION}

Utilization of WDM with FSO system has been proved to be more effective in augmenting data rates. In this paper $2 \times 10$ Gbps RZ encoded WDM Free Space Optics has been investigated. Two channel each carrying $10 \mathrm{Gbps}$ data with RZ encoding has been sent over $20 \mathrm{Km}$ long FSO channel. The received results have been tested in terms of minimum BER, maximum $\mathrm{Q}$ factor and Eye patterns. The reported results indicate successful transmission of the information in both the channels.

\section{REFERENCES}

[1] Olivier Bouchet, Hervé Sizun, Christian Boisrobert, Frédérique de Fornel, Pierre-Noël Favennec, Free-Space Optics: Propagation and Communication, Wiley-ISTE, ISBN: 978-0-470-39441-0 (2010) 1-219.

[2] J. He, R.A. Norwood, M.B. Pearce, I.B. Djordjevic, M. Cvjetic, S. Subramaniam, R. Himmelhuber, C. Reynolds, P. Blanche, B. Lynn, N. Peyghambarian, A survey on recent advances in optical communications, Comput. Electr. Eng. 40 (2014) 216-240.

[3] M. Khalighi and M. Uysal, Survey on Free Space Optical Communication, A Communication Theory Perspective," IEEE Commun. Surveys \& Tutorials 16 (2014) 2231-58.

[4] K. Kazaura et al., Experimental Demonstration of NextGeneration FSO Communication System, Optics East 2006, Int'l. Society for Optics and Photonics, (2006) 63 
$900-63912$.

[5] Sushank Chaudhary, Angela Amphawan, Kashif Nisar, Realization of free space optics with OFDM under atmospheric turbulence, Optik-International Journal for Light and Electron Optics 125 (2014) 5196-5198.

[6] Wei Liu, Wenxiao Shi, Jingtai Cao, Yaowen Lv, Kainan Yao, Shuai Wang, Jihong Wang, Xuefen Chi, Bit error rate analysis with real-time pointing errors correction in free space optical communication systems, Optik International Journal for Light and Electron Optics 125 (2014) 324-328.

[7] Flohberger, M, Gappmair and Koudelka, W., Error performance of coded FSO links in Turbulent atmosphere modeled by Gamma Gamma distribution, IEEE Transactions on wireless communications 8 (2009) $2209-2213$.

[8] E. Lee and V. Chan, Part 1: Optical communication over the clear turbulent atmospheric channel using diversity, IEEE Journal on Selected Areas in Communications 22 (2004) 1896-1906.

[9] T. Tsiftsis, H. Sandalidis, G. Karagiannidis, and M. Uysal, Optical wireless links with spatial diversity over strong atmospheric turbulence channels, IEEE Transactions on Communications 8 (2009) 951-957.

[10] Mohammad Abtahi, Suppression of Turbulence-Induced Scintillation in Free-Space Optical Communication Systems Using Saturated Optical Amplifiers, IEEE 24 (2007) 4966 - 4973

[11] Sandalidis Harilaos G., Coded Free space optical links over strong turbulence and misalignme Fading channels, IEEE 59 (2011) 1389-1399.

[12] Chaudhary S, Amphawan A. The role and challenges of free space optical systems. J Opt Commun. 2014;35:327-34.

[13] Chaudhary S, Amphawan A, Nisar K. Realization of free space optics with OFDM under atmospheric turbulence. Optik Int J Light Electron Optics. 2014;125:5196-8.

[14] Chaudhary S, Sharma A. 6 × 20 Gbps long reach WDMPI based high altitude platform inter-satellite communication system. Int J Comput Appl. 2015;122:22.

[15] Chaudhary S, Sharma A, Chaudhary N. $6 \times 20$ Gbps hybrid WDM-PI inter-satellite system under the influence of transmitting pointing errors. J Opt Commun. 2016;37:375-9.

[16] Sharma A, Chaudhary S, Thakur D, Dhasratan V. A costeffective high-speed radio over fibre system for millimeter wave applications. J Opt Commun. Published Online 15 December 2017. DOI:10.1515/joc-2017-0166.

[17] Chaudhary S, Chauhan P, Sharma A. High speed $4 \times 2.5$ Gbps-5 GHz AMI-WDM-RoF transmission system for WLANs. J Opt Commun. Published Online 18 July 2017. DOI:10.1515/joc-2017-0082.

[18] Chaudhary S, Thakur D, Sharma A. 10 Gbps-60 GHz RoF transmission system for $5 \mathrm{G}$ applications. J Opt Commun. Published Online 22 July 2017. DOI:10.1515/joc-2017-0079.

[19] Kapoor R, Sharma A, Chaudhary S. Empirical evaluation of 4 QAM and 4 PSK in OFDM-based inter-satellite communication system. J Opt Commun. Published Online 29 June 2017. DOI:10.1515/joc-2017-0059.

[20] Sharma A. Neetu, analysis and mitigation of receiver pointing error angle on inter-satellite communication. Int J Innov Tech Res. 2015 Nov;3:2540-44.

[21] Chaudhary S, Sharma A. Neetu, "6 x 20 Gbps long reach WDMPI based high altitude platform inter-satellite communication system. Int J Comput Appl. 2015 July;122:41-5.

[22] Rana S, Sharma A. Comprehensive study of radio over fiber with different modulation techniques - a review. Int J Comput Appl. 2017 Aug;170:22-5. DOI:10.5120/ijca2017914829.

[23] Sharma A, Thakur D. A review on wlans with radioover-fiber technology. Int J Electron Commun Eng. 2017 Aug;6:1-6.

[24] Thakur K, Sharma A. Comparison of MDRZ, CSRZ and DRZ schemes using different communiation channels. Int J Comput Appl. 2017 Aug. DOI:10.5120/ijca2017915106.

[25] Thakur K, Sharma A. Study of radio over fiber with different coding channel - a review. Int J Comput Appl. 2017 Aug. DOI:10.5120/ijca2017915033.

[26] Sharma A, Chauhan P. A study of radio over fiber technology in WLAN applications. Int J Res Appl Sci Eng Technol. 2017 August;5:416-20.

[27] Sharma A, Kapoor R. Study of various challenges in is OWC: a review. Int J Res Appl Sci Eng Technol. 2017 August;5:802-07.

[28] Sharma A, Rana S. Implementation of radio over fiber technology with different filtration techniques. Int J Res Appl Sci Eng Technol. 2017 August;5:783-89.

[29] Sharma A, Chauhan P. High speed radio over fiber system for wireless local area networks by incorporating alternate mark inversion scheme. J Opt Commun. 2018. DOI:10.1515/joc-2018-0084.

[30] Amphawan A, Chaudhary S, Free-space optical mode division multiplexing for switching between millimeterwave picocells, In: International Conference on Optical and Photonic Engineering (icOPEN2015), 2015 95242H-95242H-6.

[31] Amphawan A, Chaudhary S, Chan V. $2 \times 20$ Gbps-40 GHz OFDM Ro-FSO transmission with mode division multiplexing. J Eur Opt Soc Rapid Publ. 2014;9:14041 $(1-6)$.

[32] Amphawan A, Chaudhary S, Din R, Omar MN, "5 Gbps HG 0,1 and HG 0, 3 optical mode division multiplexing for RoFSO," in signal processing \& its applications (CSPA), 2015. IEEE $11^{\text {th }}$ International Colloquium on 2015:145-9.

[33] Amphawan A, Chaudhary S, Elfouly T, Abualsaud K. Optical mode division multiplexing for secure Ro-FSO WLANs. Adv Sci Lett. 2015;21:3046-9.

[34] Bansal U, Kaur K, Chaudhary S. Role of laser linewidth in high speed DWDM system by incorporating duobinary modulation scheme. Int J Comput Appl. 2015;109:30-2.

[35] Chaudhary S, Amphawan A. High-speed millimeter 
communication through radio-over-free-space-optics network by mode division multiplexing. Opt Eng. 2017;56:116112.

[36] Chaudhary S, Bansal P, Lumb M. Effect of beam divergence on WDM-FSO transmission system. Int $\mathbf{J}$ Comput Appl. 2014;93:28-32.

[37] Chaudhary S, Bansal P, Singh G. Implementation of FSO network under the impact of atmospheric turbulences. Int J Comput Appl. 2013;75:34-8.

[38] Chaudhary S, Chaudhary N, Sharma S, Choudhary B. High speed inter-satellite communication system by incorporating hybrid polarization-wavelength division multiplexing scheme. J Opt Commun. 2017;39:87-92.

[39] Chaudhary S, Sharma S. Role of turbulences in WDMpolarization interleaving scheme based inter-satellite communication system. Int J Comput Appl. 2014;104:17.

[40] Kaur P, Kaur R, Chaudhary S. Implementation of high speed long reach hybrid radio over multimode transmission system. Int J Comput Appl. 2014;91:42-7.

[41] Kaur R, Chaudhary S. Simulative investigation of laser line-width and channel spacing for realization of DWDM systems under the impact of four wave mixing. J Opt Commun. 2014;35:157-65.
[42] Sharma V. High speed CO-OFDM-FSO transmission system. Optik Int $\mathbf{J}$ Light Electron Optics. 2014;125:1761-3.

[43] Sharma V, Chaudhary S. Implementation of hybrid OFDM-FSO transmission system. Int J Comput Appl. 2012;58:37-40.

[44] Sharma V, Kumar S. Empirical evaluation of wired-and wireless hybrid OFDM-OSSB-RoF transmission system. Optik Int $\mathrm{J}$ Light Electron Optics. 2013;124:4529-32.

[45] Amphawan A, Chaudhary S, Neo T-K. HermiteGaussian mode division multiplexing for free-space optical interconnects. Adv Sci Lett. 2015;21:3050-53.

[46] Upadhyay KK, Srivastava S, Shukla N, Chaudhary S. High-speed 120 Gbps AMI-WDM-PDM free space optical transmission system. J Opt Commun. 2017.

[47] Chaudhary S, Lin B, Tang X, Wei X, Zhou Z, Lin C, et al. 40 Gbps-80 GHz PSK-MDM based Ro-FSO transmission system. Opt Quant Electron. 2018;50:321. Doi:10.1007/s11082-018-1592-z.

[48] Chaudhary S, Amphawan A. High speed MDM-Ro-FSO communication system by incorporating AMI scheme. Int J Electron Lett. OI:10.1080/21681724.2018.1494318. 